Referencia para citar este artículo: Morales-Barrera, M. C. (2018). Hacia un entendimiento del aprendizaje en entornos digitales-Implicaciones para la educación. Revista Latinoamericana de Ciencias Sociales, Niñez y Juventud, 16(1), 375387. doi:10.11600/1692715x.16123

\title{
Hacia un entendimiento del aprendizaje en entornos digitales-Implicaciones para la educación*
}

\author{
Magda ConCEPCIÓN Morales-BarRera ** \\ Profesora Tecnológico Nacional de México, México.
}

\section{Artículo recibido en febrero 2 de 2017; artículo aceptado en abril 17 de 2017 (Eds.)}

- Resumen (analítico): el presente artículo deriva de una investigación cuyo objetivo fue analizar las características del aprendizaje, basadas en las habilidades digitales que los individuos jóvenes de educación superior desarrollan en entornos socioculturales digitales no escolares. La relevancia de esta investigación estriba en que la comprensión analítica de estas formas de aprender permite identificar los retos que está viviendo la educación superior y las posibles formas de enfrentarlos. El abordaje metodológico es cualitativo; las técnicas de recogida de información fueron: cuestionario, grupo de discusión y grupo de enfoque. Presento aqui una lectura de los resultados mediada por la categoría analítica juventudes, desde la cual sostengo que las formas de ser joven en los entornos socioculturales digitales conlleva formas inéditas de aprender y de entender el mundo.

Palabras clave: juventud, sociedad de la información, TIC, aprendizaje, educación superior (Tesauro de Ciencias Sociales de la Unesco).

\section{Towards an understanding learning in digital socio-cultural environments and the implications for education}

- Abstract (analytical): This paper describes a study that has the objective of analyzing the learning characteristics, based on digital abilities, that young people in higher education develop in non-school digital socio-cultural environments. The relevance of this research is that the analytical understanding of these forms of learning contributes to identifying the challenges for higher education and possible ways to solve them. The methodological approach used is qualitative and the information collection techniques included: questionnaires, discussion groups and focus groups. The results are mediated by the analytical category of young people. The author concludes that the forms of being young in digital socio-cultural environments entail unprecedented ways of learning and understanding the world

Key words: Youth, Information Society, ICT, Learning, Higher Education (Social Sciences UnescoThesaurus).

\footnotetext{
* Este artículo de investigación científica y tecnológica presenta resultados de la investigación finalizada denominada «Los entornos socioculturales digitales, su influencia en el aprendizaje y desarrollo de Habilidades Digitales (Hadi), presentado por el Cuerpo Académico Estudios en Cultura Digital, sus implicaciones en la educación y la difusión de la ciencia; financiado por el Programa para el Desarrollo Profesional Docente, para el tipo Superior (Prodep), en el marco de la Convocatoria 2015 para el Fortalecimiento de Cuerpos Académicos, Secretaría de Educación Pública, con el número de registro IDCA-21461, con vigencia de marzo de 2015 a marzo de 2016. Área: Sociología, subárea: Sociología.

* Doctora en pedagogía por la Universidad Nacional Autónoma de México, Maestra en Educación por la Universidad Autónoma de Chiapas. Profesora de tiempo completo titular C en el Centro Interdisciplinario de Investigación y Docencia en Educación Técnica (Ciidet). Orcid: 00000003-2329-4665. Índice H5: 1. Correo electrónico: mmorales@ciidet.edu.mx
} 


\section{À uma compreensão da aprendizagem em ambientes digitais e implicações para o ensino}

- Resumo (analítico): Este artigo deriva de uma pesquisa destinado a analisar as caracteristicas de aprendizagem, com base em competências digitais, que os estudantes do ensino superior adquiram em ambientes socioculturais digitais não-escolares; a relevância desta pesquisa é que a compreensão analítica dessas formas de aprendizagem permitem identificar os desafios experimentados no ensino superior e as possiveis formas de resolvêlos. A abordagem metodológica foi qualitativa, as técnicas de recolha de informação foram: questionário, grupo de discussão e grupo de foco. A leitura dos resultados foi feita a partir da categoria analítica da juventude, a partir do qual argumenta-se que os modos de ser jovem em ambientes socioculturais digitais traz novas formas de aprendizagem e compreensão do mundo apresentado.

Palavras-chave: juventude, sociedades da informação, TIC, aprendizagem, educação superior (Thesaurus de Ciências Sociais da Unesco).

-1. Introducción. -2. Metodología. -3. Juventudes como categoría analítica, lectura desde una perspectiva de construcción histórica. -4. Juventudes en los entornos socioculturales digitales. -5. Juventudes en la educación superior. -6. Conclusiones. -Lista de referencias.

\section{Introducción}

Este artículo se deriva de una investigación cualitativa realizada con el objetivo de analizar las características del aprendizaje, basadas en las llamadas habilidades digitales, que los sujetos jóvenes de educación superior desarrollan en entornos socioculturales digitales no escolares; el supuesto que sostengo en este trabajo analítico consiste en que la cibercultura genera habilidades digitales que devienen en formas de aprendizaje distintas a las previstas por la institución escolar, generando retos a los sistemas de educación superior que, al menos en México, se reconocen pero no se está respondiendo a estas de la manera radical y rápida que las sociedades del conocimiento exigen.

Es importante precisar que, atendiendo la complejidad del objeto de estudio, se han realizado distintas lecturas de la información obtenida. En ese contexto, en este artículo reporto los resultados de la investigación a partir de la categoría juventudes, la cual consideré como una herramienta analítica importante en tanto posibilita la comprensión de las construcciones subjetivas de las personas jóvenes y las formas en que están participando en los entornos socioculturales digitales.

Esta consideración resultó de que, en los primeros acercamientos al objeto de estudio, en la investigación me encontré con la limitante de que el sentido común, que restringe la juventud a una condición etaria, suele permear la mayoría de las investigaciones sobre la gente joven, ocultando las diversas y complejas relaciones que históricamente se han establecido entre juventud y edad (Semán, 2015) y reduciendo la juventud a una variable demográfica.

Trabajar el concepto como categoría analítica, requirió de un ejercicio deconstructivo para poner sobre la mesa de discusión las condiciones que atraviesan la construcción histórica de la juventud; esto devela elementos que permiten cuestionar los significados sedimentados, producidos desde marcos deterministas - biológico, psicológico, social y ahora tecnológico-, que suponen la existencia «natural», y por tanto universal, de la juventud.

\section{Metodología}

Entiendo método como un trayecto construido por el sujeto investigador para acercarse-construir el conocimiento sobre un objeto de estudio; de esto resulta relevante destacar dos condiciones: la primera tiene que ver con el carácter histórico de la construcción metodológica, que impide que un método sea absoluto e infalible, como un camino que una vez trazado puede ser seguido incontables veces, llegando siempre a los mismos resultados. 
La segunda condición implica una postura epistemológica que nos sitúa en una perspectiva interpretativa desde la cual asumimos que los resultados obtenidos no develan una propiedad inmanente al objeto de estudio, ni constituyen la verdad absoluta sobre este.

En concordancia con este posicionamiento y con la asunción del aprendizaje como un proceso de base sociocultural, tomamos la decisión de realizar una investigación cualitativa que, desde una mirada comprensiva y situada, brinde elementos para conocer las habilidades que los individuos jóvenes de educación superior están desarrollando en los entornos socioculturales digitales no escolares, y sus implicaciones para el aprendizaje.

Utilizamos como técnicas de recolección de información: 1) un cuestionario, dirigido a conocer los usos de Internet y las principales actividades que los jóvenes y las jóvenes realizan en los entornos socioculturales digitales; 2) dos grupos de discusión, los cuales tuvieron como eje las formas de aprender, pensar y ser de los sujetos jóvenes en las sociedades del conocimiento; y 3) un grupo de enfoque dirigido hacia la exploración de cómo las personas jóvenes están significando la educación y los procesos de aprendizaje en entornos escolares y no escolares.

En la investigación participaron 23 estudiantes de licenciatura de edades entre $19 \mathrm{y}$ 26 años (12 mujeres y 11 hombres), provenientes de seis instituciones de educación superior(IES), de las cuales tres son públicas y tres privadas. Conviene precisar que el estudio lo hicimos en la ciudad de Querétaro, que por su creciente población y su economía industrializada resulta una de las más importantes en México; el Inegi (2017) reporta que el $60.2 \%$ de la población de esta ciudad se considera usuario de Internet ${ }^{1}$, dato que la ubica en el séptimo lugar a nivel nacional, donde el promedio de la población urbana que es usuaria de Internet es de 59.5\%.

Por otro lado, la Primera Encuesta Nacional sobre Consumo de Medios Digitales y Lectura (Ibby México, 2015), encontró que

$1 \quad$ El Inegi (2017) define como usuario de Internet al «Individuo de seis o más años que en forma eventual o cotidiana, y de manera autónoma, ha accedido y realizado alguna actividad en Internet en los últimos doce meses».

Rev.latinoam.cienc.soc.niñez juv 16 (1): 375-387, 2018 http://revistalatinoamericanaumanizales.cinde.org.co doi: $10.11600 / 1692715 x .16123$ la proporción de jóvenes ${ }^{2}$ de zonas urbanas usuarios de Internet es del 87\%; esto indica una importante penetración de Internet en este grupo poblacional, puesto que la media nacional para la población total es de $54 \%$.

Aunque la investigación realizada no se hizo en términos cuantitativos, conviene precisar el alto involucramiento en los entornos socioculturales digitales de las personas jóvenes que participaron en el estudio; al respecto, en el cuestionario aplicado, 21 de los 23 participantes manifestaron estar conectados a Internet más de la mitad del día; los otros dos señalaron que se conectan solo cuando no están en la escuela. Respecto a los lugares principales en los que establecen la conexión, 11 participantes señalaron una conexión a Internet permanente (en todo lugar), siete ubicaron el hogar y cinco la escuela como principal lugar para establecer la conexión. En cuanto al dispositivo utilizado, 20 refirieron el Smartphone.

Estos datos permiten caracterizar a los sujetos jóvenes que participaron de esta investigación, quienes tienen condiciones privilegiadas; con esto quiero enfatizar la imposibilidad de generalizar los hallazgos de la investigación; la coincidencia de este acercamiento con las situaciones que viven jóvenes que habitan otros contextos debe leerse con las precauciones y matices que correspondan.

\section{Juventudes como categoría analítica, lectura desde una perspectiva de construcción histórica}

Juventudes es la categoría analítica que orientó las interpretaciones que propongo en este apartado; entendida desde una perspectiva de construcción histórica, esta categoría permite tomar distancia de las miradas homogeneizadoras que se asumen capaces de decirlo todo sobre los individuos jóvenes y sus formas de aprender, pensar y actuar en los entornos socioculturales digitales, deviniendo en una esencialidad de la juventud, basada en la impronta tecnológica.

2 En dicho estudio se define como jóvenes a las personas de entre 12 y 29 años de edad. 
Plantear la construcción histórica de la juventud entraña un cuestionamiento profundo al sentido común que asume la existencia natural y universal - de la juventud; esto no quiere decir que no haya en la realidad empírica personas jóvenes. En este sentido, Brito (1996) señala las carencias que comúnmente presentan los estudios sobre la juventud en México, tendientes a situar el objeto en una realidad empírica sin un ejercicio epistemológico que permita conceptualizarlo, lo que restringe las definiciones de juventud a la determinación de un rango de edad e impide su construcción como un objeto teórico que permita leer $\mathrm{y}$ problematizar esa realidad.

En este orden de ideas, es preciso establecer una distinción entre jóvenes y juventud; al respecto, Balardini (2000, p. 11) afirma que «jóvenes hubo siempre, pero juventud no, aunque parezca extraño; la idea de juventud está íntimamente ligada a los roles históricos de los distintos grupos sociales y etarios»». Esto conlleva el reconocimiento de la condición histórica que atraviesa la construcción de la juventud.

Ya Mead (citada en Santillán \& González, 2016, p. 119), a principios del siglo pasado, cuestionó el sentido universal de la juventud, como etapa de crisis y conflictos presente en las discusiones de su época, afirmando que «en diferentes escenarios culturales, los jóvenes presentaban condiciones distintas». Del reconocimiento de que más que una, la juventud es múltiple, distinta, contextual e histórica, ha derivado - sostiene Taguenca (2016) - la diversificación de preguntas, objetos, actores y metodologías de la sociología de la juventud.

Autores como Balardini (2000), Erazo (2009) y Ulloa (2016), sitúan la emergencia de la juventud en la sociedad burguesa. Balardini (2000) ubica algunos antecedentes de lajuventud en las ciudades-estado griegas de Esparta y Atenas donde, muy ligado a la conformación de la efebía -institución educativa orientada a la formación cívico militar-, se produjo un grupo social que se caracterizaba por dos condiciones: estar en un proceso de formación obligada para su posterior desempeño militar - y que la entrada a este proceso marcaba el fin de la infancia. Otro antecedente que ubica el autor está en la creación de la universidad de Bolonia, posible gracias a una élite de jóvenes.

Lo cierto es que estas cuasi juventudes no implicaron las mismas relaciones, roles y significados inscritos en el concepto de juventud producido en la revolución burguesa (Balardini, 2000), ligado a las relaciones sociales, políticas, económicas y culturales gestadas en la base de las sociedades capitalistas; al respecto, Erazo (2009, pp. 1306-1307) sostiene que:

Se originó en la necesidad de las naciones capitalistas de garantizar la reproducción del sistema económico y social fundamentado en los procesos de industrialización. Para ello se expande y fortalece el sistema educativo, a partir de una base hogareña que vino a conocerse como «familia nuclear».

La cita anterior señala implícitamente dos instituciones clave para el surgimiento de la juventud: la escuela y la familia. Balardini (2000) incluye la infancia, conformando así una tríada propiamente burguesa sin la cual la juventud sería impensable. En la misma cita se entrevén los nuevos sistemas de producción y reproducción que generaron relaciones de poder y necesidades de reestructuración social, dando lugar a las instituciones señaladas.

Balardini (2000, p. 13) enfatiza el papel fundante de la escuela en la construcción de la juventud, y sostiene que «va a ser el foco del nacimiento de la juventud, tal cual nosotros la conocemos». A su vez, reconoce en las necesidades de las primeras sociedades capitalistas las condiciones que posibilitaron el sistema escolar, estructurado con el objetivo de formar individuos calificados y dispuestos a integrarse a los nuevos sistemas productivos.

El hiato entre el tiempo de formación y la integración a esos sistemas fue entendido desde la noción de moratoria social; el vínculo entre moratoria social y población joven - de la clase burguesa - se naturalizó en el concepto moderno de juventud; de ahí se derivó una identificación muy fuerte entre juventud $\mathrm{y}$ estudiantes.

Ulloa (2016, p. 109) propone que a inicios del Siglo XX surge el interés científico por la condición juvenil y se generan las distinciones sobre quienes serán considerados jóvenes, marcadas por «el diferente acceso al mercado 
laboral y a la institución de procesos educativos destinados a preparar al colectivo de sujetos jóvenes para su futura inserción en el mundo adulto».

Una perspectiva que reconoce el carácter histórico de la juventud permite identificar las condiciones que dieron lugar a la emergencia y sedimentación de su significado moderno $\mathrm{y}$ reconocer las significaciones que fueron excluidas o soterradas, negando así las múltiples formas de ser joven, atravesadas por condiciones sociales, políticas, económicas, educativas y subjetivas que configuran realidades diversas que desbordan constantemente cualquier pretensión homogeneizadora. Estos planteamientos me permiten sostener el argumento central de este apartado, a saber, no existe un significado único y pleno de la juventud, que solo puede ser entendida a partir de reconocer la heterogeneidad de las diversas maneras de ser joven.

Plantear la categoría juventudes responde a la exigencia teórica y metodológica de construir una categoría analítica que libere la mirada de un concepto totalizador. Bourdieu, en 1978, invitaba a esta construcción al enfatizar en la necesidad de hablar de juventudes, considerando un abuso del lenguaje -un abuso epistemológico, podríamos completar«subsumir bajo el mismo concepto universos sociales que no tienen prácticamente nada en común» (Citado en Santillán \& González, 2016, p. 124).

La pluralización del término implica una perspectiva epistemológica de lo juvenil (Duarte, 2000) basada en el reconocimiento de la heterogeneidad como eje de las múltiples construcciones subjetivas que no pueden subsumirse en una identidad cerrada; desde ese lugar de mirada, la categoría juventudes tiene dos implicaciones importantes: la erosión del supuesto de identidad de la juventud y la exigencia de historizar la producción de subjetividades juveniles.

Pensar en juventudes representa un giro que deconstruye el supuesto de identidad, bajo el que son invisibilizadas distintas condiciones $\mathrm{y}$ formas de ser joven, conteniendo un problema político relevante, a saber, la exclusión de todo lo que no cabe en el marco identitario de la juventud. In-significantes, porque el nombre no las nombra; las referencias empíricas a esta exclusión son muchas para mencionarlas todas; entre las más recalcitrantes podrían citarse: indígenas, campesinos y campesinas, empleadas domésticas, obreros y obreras, sexoservidoras, jóvenes que viven al margen de la juventud por múltiples condiciones - económicas, políticas, sociales, culturales, étnicas, de género-, y que poco han interesado a los estudiosos sobre la juventud.

En tal sentido, Kropff y Stella (2017) se proponen sistematizar la producción relacionada con problemáticas situadas en la intersección entre la condición étnica y la condición juvenil en Latinoamérica; según las autoras, esta producción es dispersa, y hasta mediados del siglo XXI era prácticamente ausente.

Lo radical de la categoría juventudes es la propuesta de dislocar el concepto, quitarle su centro de sentido situando esas exclusiones no afuera sino adentro, en su propia médula, para entender la diferencia como su eje, dando sentido a las construcciones subjetivas que no pueden ser homogeneizadas bajo ningún significado absoluto, para así erosionar «la imagen universalizante y hegemónica de la multiplicidad de modos de estar siendo joven hoy en nuestros países» (Elizalde, 2015, p. 134).

\section{Juventudes en los entornos socioculturales digitales}

«La humanidad ha nacido varias veces, antes de sapiens, durante sapiens y después de sapiens, y quizá se prepara un nuevo nacimiento para ella, en una época futura» (Morin, 2000, p. 64).

En este apartado pongo en discusión las condiciones y escenarios de las actuales sociedades del conocimiento y sus implicaciones en la construcción de juventudes; por ello es importante reconocer las nuevas configuraciones sociales, culturales, políticas y económicas, gestadas a partir - pero no solode los avances tecnológicos, sobre todo del área de la telemática, que abrieron espacios de posibilidad para la emergencia de nuevas lógicas de construcción social y subjetiva; asistimos a 
la época futura que anticipaba Morin (2000), en la que la humanidad está renaciendo.

En estos escenarios, las juventudes juegan un papel protagónico del que en otros momentos históricos fueron relegadas, sobre todo por la estructura sociopolítica vertical, centrada en la transmisión de la cultura adulta a las gentes jóvenes, desde donde la juventud fue entendida como una etapa en la que la persona se prepara mediante esa transmisión para pensar y actuar la vida adulta.

Uno de los cambios más importantes generados en las sociedades del conocimiento consiste precisamente en que, mediados por las TIC, se han posibilitado procesos disruptivos que propician «relaciones sociales más horizontales y flexibles» (García, 2012, p. 5). Con base en el paradigma de interconexión de la world wide web (www), se dislocaron múltiples fronteras que otrora limitaban los ámbitos de participación y reflexión social (geográficas, institucionales, generacionales, disciplinares), deconstruyendo dicotomías supuestas por categorías tales como generación, género y clase.

Es importante enfatizar que, si bien hay una base tecnológica sin la cual no hubieran sido posibles los procesos mencionados, la lógica de las redes que sostiene la www no emerge de esta en términos de causa-efecto, por lo que su relación con la reconfiguración sociocultural no es lineal ni homogénea. Al respecto, Lévy (2004) cuestiona la idea de que las TIC impactan sobre ámbitos socioculturales, muy difundida y poco cuestionada en los espacios de producción académica; esta idea implica un determinismo tecnológico que deriva en un planteamiento ahistórico de la relación entre tecnología, sociedad y cultura, concebida de manera unidireccional, mecánica y reduccionista.

Partiendo de este cuestionamiento, el autor propone que tecnología, sociedad y cultura pueden pensarse como sistema de interacciones e interrelaciones intrínsecas y mutuamente constitutivas. Desde estos planteamientos se puede sostener que los alcances de la tecnología digital exceden lo técnico (uso de artefactos y plataformas) para arribar a redimensionamientos ontológicos y epistemológicos que permiten otras maneras de ser, pensar y actuar lo social.
Es innegable que los individuos jóvenes son actores clave en esos escenarios, desde donde se han resituado para configurar nuevas formas de participación basadas en la lógica de las redes, que podrían entenderse como estructuraciones horizontales, sin centro, fundadas en la heterogeneidad y la diferencia, con formaciones diversas y múltiples posibilidades de extensión, que dan lugar a la proliferación y a la constitución de nodos de sentido.

En los hiatos de posibilidad abiertos por las redes, se construyen múltiples juventudes que erosionan las formas tradicionales que la sociedad había asignado al ser juvenil y permiten pensar lo social desde lugares inéditos. Es importante enfatizar que, precisamente por esta multiplicidad, es un contrasentido asumir que hay un principio tecnológico que determina una identidad inmanente y homogénea de la juventud.

Esta tesis apunta a tomar precauciones con nociones que generalizan las características de la juventud actual, basadas en dos condiciones erigidas como categorías fundamentales: la edad y la impronta tecnológica; por ejemplo nativos digitales (Prensky, 2010), que intenta definir a todos los sujetos jóvenes por igual, desde una perspectiva dicotómica que traza una frontera casi inamovible. El riesgo de este planteamiento estriba en que soterra las diversas condiciones que se entretejen en las construcciones subjetivas e intenta borrar las diferencias en un «todos» que funciona como identidad objetiva — cerrada y plena de sentido-; la diferencia está situada afuera de esa identidad.

Si bien numerosos estudios sostienen que «los jóvenes están más avanzados que el resto de la población en el acceso y manejo de las tecnologías comunicacionales») (García, 2012, p. 8), incluyendo a los de menos recursos que, aunque no tengan un equipo de cómputo o conexión a Internet en su casa, tienen acceso desde otros lugares (cibercafés, escuelas, plazas públicas), hay múltiples condiciones - sociales, culturales, económicas, políticas, educativas - que implican diferentes accesos, usos y apropiaciones de estas tecnologías. Por ello, puedo sostener que las brechas digitales 
no solo existen como fronteras que separan dos identidades cerradas — jóvenes-adultos, alumnos-docentes, nativos-migrantes - sino que atraviesan y desbordan estas identidades, haciendo que las miradas en blanco y negro no sean suficientes para explicarlas.

Esto no quiere decir que desconozca las implicaciones que han tenido los avances en tecnología digital en nuestras sociedades y también en nuestras subjetividades; mi invitación es a pensarlas desde un lugar no determinista. La propia lógica de las redes que permea lo digital está basada en la diversidad y la diferencia, en la deconstrucción de los centros absolutos y en la apuesta por la multiplicidad; de ahí que resulte contradictorio querer fijar, en una identidad definitiva y definitoria, la heterogeneidad constitutiva de las juventudes, que han encontrado en estos escenarios lugares de posibilidad para ser joven más allá de lo esperado y de lo previsto.

Es innegable que «este entorno tecnológico ha modificado en los jóvenes sus comportamientos individuales, colectivos y los modelos organizativos relacionados con la cultura, el ocio, el trabajo y la educación como también la participación política y ciudadana» (Ortega, 2012, p. 111); sin embargo, estas modificaciones no son unidireccionales, homogéneas y determinadas por el mero uso tecnológico, y no todas las personas jóvenes tienen las mismas oportunidades de acceso, por lo que no es posible universalizar sus efectos. Tener precauciones con las miradas deterministas no impide reconocer convergencias en las juventudes contemporáneas, en tanto que:

Las nuevas generaciones han transformado las redes en lugares para habitar e interactuar, es decir, en lugares en el sentido antropológico del término. Muchos jóvenes de este nuevo milenio no están ni en la esquina ni en el boliche, ni tampoco en el pool del barrio. Para poder «escucharlos»y «verlos» interactuando, hay que dirigirse a otros lados (Balaguer, 2014, p. 13).

Desde estos argumentos, propongo entender estos lugares como entornos socioculturales digitales: espacios relacionales soportados por tecnología digital que emergieron principalmente a partir del desarrollo de la web
2.0, abriendo las posibilidades interactivas en las plataformas de información y comunicación; estos entornos se entienden como socioculturales en tanto generan sentidos sociales y permiten el intercambio - en términos de producción y consumo - de contenidos culturales.

En los entornos socioculturales digitales se están constituyendo nuevas formas de comunicación y relación social que trascienden los límites, configurando un espacio globaldeslocalizado y un tiempo a la vez eterno y efímero, «el tiempo de los hipertextos pero también de los microrrelatos, de las microculturas y de los microsegundos» (Feixa, Fernández-Planells, \& Figueras-Maz, 2016, p. 114), en los que se establecen condiciones distintas a los espacios sociales tradicionales; en seguida se mencionan tres de las que pueden ser consideradas como nodales en la construcción de las subjetividades juveniles.

Laprimeracondicióneslahiperconectividad, que permite trascender límites espaciotemporales abriendo la posibilidad de múltiples y constantes conexiones con muchos otros, no necesariamente próximos -en términos de ubicación geográfica, clase, adscripción institucional, edad, géneros, nacionalidades, lenguajes - Algunos individuos jóvenes ubican en las redes sociales espacios en los que pueden establecer relaciones con otros con quienes comparten intereses comunes; por ejemplo, los relacionados con la formación profesional.

Muchas personas creen que Facebook es totalmente para perder el tiempo $y$, en mi caso, a mí me gusta mucho interactuar por medio de redes sociales lo que yo estudio, economía, hay con quien debatir, con quien hacer, intercambiar opiniones (Mujer, 26 años).

Aunada a esta, la desterritorialización genera una suerte de ubicuidad; los sujetos jóvenes no tienen necesidad de abandonar su habitación para vivir experiencias e interacciones absolutamente variadas; por ejemplo, establecer un noviazgo con una chica filipina, jugar online con un argentino, tomar un curso de Harvard; esta condición posibilita formas complejas de colaboración, a través 
de las cuales los estudiantes pueden construir nuevas experiencias de aprendizaje.

Hablando de colaboración, foros de discusión... a mí me encanta trabajar con google docs, con google drive, con videoconferencias, es muy útil... cuando no tienes tiempo de estar viendo a las personas frente a frente $y$ cuando tampoco tienes la posibilidad (Hombre, 22 años).

Otra condición interesante es la Outimidad, que implica un constante desbordamiento de lo privado que desdibuja y tensiona los límites con lo público, subvirtiendo la otrora pregunta por la intimidad «¿qué hago público?», para reformularla en los términos de «¿Qué hago privado? » (Balaguer, 2014, p. 16).

En redes sociales si hay mucha participación, pero se dicen cosas que tal vez no dirías (Mujer, 23 años).

La vida en red es pública; es, por definición, compartida; esto conlleva la constante necesidad de establecer políticas de privacidad que permiten diferenciar las audiencias a las que están dirigidas $-\mathrm{O}$ al menos permitidas - las distintas enunciaciones que se suben a las redes; sin embargo estas tienen la potencia de emanciparse de los deseos e intenciones del enunciador para fluir sin freno por la www; «La replicabilidad de lo digital es prácticamente incontrolable. Las redes reverberan las informaciones, las distribuyen y las desparraman como memes. De eso se trata justamente la «viralidad» de la red» (Balaguer, 2014, p. 16).

Todas las circunstancias que pasan las volvemos algo gracioso... se vuelve viral... le damos una importancia y dejamos de ver otras cosas que son importantes... esta popularidad... los memes, da risa, pero después de cierto tiempo ya no da risa... pasa a la historia y deja de tener ese sentido (Mujer, 19 años).

Las condiciones presentadas han contribuido a que las juventudes que habitan e interactúan en los entornos socioculturales digitales no se estructuren en torno a un principio identitario cerrado y determinado, sino que se configuren desde la misma lógica, abierta y sin centro, de la red. De ahí las formas diferenciadas de ser joven que se producen entre los distintos actores juveniles e incluso en un mismo actor que puede representar formas diferentes de ser para distintos públicos, y responder a múltiples necesidades y exigencias.

Es crear una identidad falsa, creerte tu propia mentira, subir cosas no porque las creas realmente sino porque quieres quedar bien con tu grupo de amigos, al grupo al que perteneces...; creas una identidad y cuando dices muchas mentiras te las crees..., te creas tu propia vida social en redes sociales y es muy diferente a tu vida social que llevas como persona (Hombre, 20 años).

Una situación inédita que están viviendo las juventudes contemporáneas tiene que ver con la marcada tensión, que se puede entrever en el fragmento anterior, entre quienes son en los entornos socioculturales digitales — ser expresado sobre todo en redes sociales - y en los contextos presenciales de relación social. En ese sentido, encontré opiniones encontradas entre los sujetos jóvenes, pues por un lado hay quienes consideran que existe cierto desdoblamiento entre el sí de la vida online y el sí de la vida offline.

Muchas personas en la actualidad en las redes sociales publican cosas para pertenecer a un grupo, quizás no las piensen, no es como cuando entablamos una conversación cara a cara que si le echas un poco de pensamiento a lo que vas a decir... pero en redes sociales haces lo que consideras necesario para pertenecer (Mujer, 23 años).

Este fragmento apunta otro elemento interesante, relacionado con la pertenencia social; esto conlleva a convenir en que efectivamente los entornos socioculturales digitales están constituyéndose en espacios en los que los jóvenes y las jóvenes buscan una pertenencia. Esta pertenencia resulta, sin embargo, en ocasiones distinta e incluso opuesta a la cotidianeidad offline.

Por otro lado, hay que considerar que en los entornos socioculturales digitales se están 
construyendo espacios de participación en los que los individuos jóvenes pueden mostrar su descontento con la realidad social del país y del mundo, lo que rompe la aparente dicotomía entre vida online-vida offline, para mostrar imbricaciones entre estos ámbitos.

La juventud es una juventud inconforme, enojada por los problemas diarios que enfrenta nuestra sociedad y sí... se aprovechan de este anonimato para comentar este tipo de cosas negativas o positivas con la tranquilidad de que quizá nadie va a saber que eres tú (mujer, 23 años).

Como lo denota el fragmento anterior, un elemento productor de estas imbricaciones tiene que ver con una inconformidad que hace parte del ser joven; esta inconformidad es llevada a los entornos socioculturales digitales en donde además de expresarse, puede diseminarse hasta hacerse viral y extenderse a contextos sociales no digitales.

Incluso, la participación deriva en eventos... en redes sociales se expresan las opiniones y con base en esas opiniones se genera un evento, las personas que están de acuerdo invitan al evento y se hace más grande (Hombre, 20 años).

La vida on line, a la vez imbricada y a la vez distinta de la vida off line, pone en evidencia el desbordamiento constante del supuesto de identidad para mostrar la heterogeneidad inerradicable y constitutiva del sujeto como ser social.

\section{Juventudes en la educación superior}

Si bien el concepto moderno de juventud surgió a partir de la invención de la escuela en una clase social determinada, las nuevas formas de ser joven en los entornos socioculturales digitales están replanteando desde la médula el concepto de educación, y deconstruyendo los sistemas de educación superior, basados en su mayoría en una concepción educativa reducida a la transmisión - lineal y unidireccionalde la información, seleccionada y organizada en torno a intereses políticos, económicos y sociales, con el objetivo de preparar a las

Rev.latinoam.cienc.soc.niñez juv 16 (1): 375-387, 2018 http://revistalatinoamericanaumanizales.cinde.org.co doi: $10.11600 / 1692715 \times .16123$ personas jóvenes para que ocupen un lugar en la sociedad adulta; de ahí que realizar estudios de educación superior, hasta hace apenas algunos años, significara para la mayoría de los jóvenes y las jóvenes en México el único camino, o al menos el más transitable, para «ser alguien en la vida».

Los entornos socioculturales digitales y las nuevas formas de aprendizaje que están generando, plantean retos a la educación superior, a los cuales esta ha intentado responder de distintas maneras; en términos de la relación IES-TIC podría ubicarse tres respuestas:

a) Inclusión de tic en el aula, reducida muchas veces a la cuestión infraestructural y técnica; esto es, dotar de equipos y conexiones, incentivar el uso de herramientas - tanto de hardware como de software-, apelar a la integración de plataformas educativas $y$ redes sociales como apoyo a la presencialidad (blended learning), entrenar a los sujetos docentes en las habilidades técnicas mínimas requeridas para el uso de estas herramientas; sin embargo, esta apuesta por la tecnologización del aula puede ser riesgosa si se aborda de esta manera porque, por un lado la importancia de las TIC en la educación es reducida a los «fierros» ${ }^{3}$ y al uso de estos $\mathrm{y}$, por otro, dejan de ser vistas como medios y herramientas para la educación y se tornan en un fin en sí mismo, como si bastara incluirlas para resolver todos los problemas educativos.

b) Incursión en los entornos virtuales, mediante plataformas dedicadas a generar espacios en los que tiene lugar el proceso enseñanzaaprendizaje (educación a distancia, educación virtual, programas educativos no escolarizados); estos suelen implicar un cambio de formato que sugiere apoyarse en el e-learning, pero por lo general no cuestionan las concepciones centrales de la escolaridad ni su estructura vertical; de esto resulta, en

3 Expresión más o menos común para referirse al hardware. 
ocasiones, una traslación de la escuela al espacio virtual.

c) Diversificación de la oferta educativa basada en formatos digitales; la diferencia con el punto anterior radica en que se exploran otros modos de aprendizaje escolar no necesariamente inscritos en un programa formal; suelen ser de corta duración, como cursos de certificación — de carácter más o menos restringido-, cursos abiertos y masivos (mooc), entre otros.

A partir de ello se han potenciado múltiples procesos de enseñanza y aprendizaje, pero algunas veces sigue primando el supuesto de transmisión de contenidos como base de este; en otras ocasiones se ensayan procesos abiertos basados en la conectividad y en la interactividad, principios del concepto de inteligencia colectiva que Lévy (2004, p. 20) sintetiza bien cuando expresa que «nadie lo sabe todo, todo el mundo sabe algo, todo el conocimiento está en la humanidad». Esto tiene múltiples repercusiones que están incidiendo en una erosión profunda de lo que tradicionalmente se entendía por proceso educativo y construcción del conocimiento.

(...) las repercusiones que ello tiene, entre otras cosas para los procesos de enseñanza y aprendizaje, la formas en que se comunican los profesores y los alumnos, las maneras de interaccionar los estudiantes con la información y los contenidos, y las exigencias que las mismas van a reclamar a los actores del acto sémico-didáctico... en la creación de nuevos escenarios de comunicación que vendrán matizados por ser: de carácter tecnológicos/mediáticos, amigables, flexibles, individualizados, colaborativos, activos, interactivos/ dinámicos, deslocalizados espacialmente de la información, pluripersonales, y pluridimensionales/multiétnicos (Cabero \& Llorente, 2008, p. 7).

Ante estos replanteamientos, en México se han generado reformas al sistema de educación superior, pretendidamente estructurales, desde las cuales se han propuesto cambios de enfoque - por ejemplo, hacia las competencias profesionales - , ampliación de la cobertura e incremento de la matrícula - realizada principalmente a partir de la iniciativa privada - , modelos de acreditación de la calidad y certificación — nacional e internacional-en aras de una mayor competitividad (Ortiz, 2017).

Sin embargo, es necesario girar el sentido desde el que se están planteando estas respuestas, que provienen desde dentro del sistema de educación superior, para reconocer que las condiciones que están desbordándolo se están produciendo fuera de el, en entornos socioculturales digitales estructurados en redes horizontales que generan espacios de acción, reflexión y participación social, en los que los jóvenes y las jóvenes tienen oportunidades de resituarse como actores sociales. Este giro conlleva aceptar lo indeterminado de las condiciones socioculturales actuales, ante las cuales se requiere mayor apertura de las IES, en tanto, más que pretender controlar estas condiciones subsumiéndolas a las lógicas institucionales, se requiere de un descentramiento que movilice las estructuras escolarizadas.

Vinculando el entendimiento de las juventudes como construcciones subjetivas heterogéneas e históricas, con los retos que los entornos socioculturales digitales están generando a la educación superior, propongo a continuación algunas interpretaciones sobre las implicaciones que las nuevas formas de ser joven tienen en la producción de nuevas formas de conocer, pensar y aprender, que están rebasando los límites de la institución escolar.

En la indagación resalto que las principales actividades que los sujetos participantes realizan en estos entornos tienen que ver con: participación en redes sociales (10), búsqueda de información no escolar (9), compartir y descargar contenidos multimedia (7), búsqueda de información relacionada con las asignaturas escolares (5), participación en juegos online (3), participación en cursos virtuales (2) destaco que estas actividades, en la mayoría de los casos, no están directamente relacionadas con el quehacer de los individuos jóvenes como estudiantes de educación superior, pero que pueden tener implicaciones en el desarrollo de

$4 \quad$ Los números entre paréntesis representan a los estudiantes y a las estudiantes que señalaron esas actividades como las principales que realizan en Internet; cabe precisar que las actividades no fueron excluyentes, por lo que la sumatoria excede el número de participantes del estudio. 
habilidades que dislocan las formas de aprender consideradas tradicionalmente por la escuela. Antes los maestros eran vistos como un conocimiento absoluto, lo que decía el maestro dentro del salón de clases era verídico y era con lo que tú te tenías que quedar; pero actualmente los maestros son - va a sonar un poco mal-, pero son una herramienta para nosotros porque nosotros investigamos más de lo que ellos nos aportan y ellos están para ayudarnos a corregir ciertas dudas, ya no es tanto de que lo que diga el maestro es verdad y aquí se termina el tema y ya no puedes investigar más, sino que son una herramienta que nos permita impulsarnos más adelante (Hombre, 22 años).

La realidad hiperconectada de las personas jóvenes estudiantes de educación superior en la ciudad de Querétaro, coincide con la afirmación de Balaguer (2014, p. 17) sobre la hiperconexión juvenil, condición que les permite traspasar los límites de la escuela, otrora concebida como espacio privilegiado de acceso a la información $\mathrm{y}$ al conocimiento.

La habitación juvenil ahora no es solo un búnker hiperconectado desde donde conectarse con los pares, sino también un lugar desde donde conectarse con el conocimiento. Y decimos bien conocimiento y no información, porque no se trata solamente de acceder a páginas web, a artículos sueltos, a algunas revistas académicas o a videotutoriales de YouTube, sino de estar en contacto con docentes y alumnos interesados en temáticas similares y ubicados en cualquier lugar del mundo (Balaguer, 2014, p. 17).

De ahí que los sujetos jóvenes ya no pueden seguir siendo considerados como ladrillos en la pared $^{5}$ de una estructura social preconcebida y rígida. Los muros de la escuela ya no contienen lo que las gentes jóvenes aprenden y conocen, pues en las sociedades y economías del conocimiento, este está en todas partes, fluye por la red a velocidades sin precedentes, haciendo imposible fijarlo, contenerlo o controlarlo.

$5 \quad$ En alusión a The Wall de Pink Floyd (1979).

Rev.latinoam.cienc.soc.niñez juv 16 (1): 375-387, 2018 http://revistalatinoamericanaumanizales.cinde.org.co doi:10.11600/1692715x.16123
Lo primero es compartir, lo más básico son los links... empieza ahí la búsqueda... empieza en las redes sociales que es lo que realmente ocupamos, ya sea un grupo de whats app o Facebook, lo que sea, pero es el hecho de compartir la información que te encuentras en la red... compartir lo que encuentras en tu búsqueda personal para llegar a una conclusión colectiva con base a varios puntos de vista (mujer, 19 años).

El conocimiento se disemina casi tan rápido como se construye, abriendo posibilidades infinitas para pensar el mundo y actuar en él. En esto radica la importancia de entender las implicaciones para la educación superior, de la participación de las juventudes en los entornos socioculturales digitales, y las formas de aprendizaje generadas, que van más allá de lo técnico, e incluso de lo cognitivo, para conformar una función central: la de estructurar las formas de pensar y actuar en el mundo.

Se trata de una forma de pensar que se unieron varias personas para construir una nueva estructura, no sabría de qué forma llamarla, pero es esa nueva forma de conocimiento que nace en esta época (Hombre, 22 años).

\section{Conclusiones}

Con los argumentos esbozados en este trabajo propongo un entendimiento histórico de las construcciones subjetivas juveniles desde donde se cuestionan las miradas que asumen un núcleo identitario homogéneo desde el cual se puede definir el ser de los jóvenes y las jóvenes en las sociedades contemporáneas, marcado por un «impacto» tecnológico. Erosionar el supuesto de identidad juvenil y situar la producción de subjetividades heterogéneas en contextos sociohistóricos particulares, permite sostener que las juventudes se construyen al tiempo que van construyendo las distintas y múltiples realidades sociales que habitan, para configurar espacios heterogéneos de posibilidad $\mathrm{y}$ resistencia.

En ese sentido, las juventudes actuales están rompiendo los límites y las dicotomías 
que restringían su actuación en los espacios sociales, entre ellos los educativos, en tanto habitar los entornos socioculturales digitales ha implicado maneras diversas de relacionarse y de interactuar con otros (pares, maestros, autores), de aprehender y construir los conocimientos (multidireccional, hipertextual, multimedial e interactivamente), propiciando la emergencia de formas alternativas y activas de aprendizaje que han requerido habilidades de pensamiento distintas a las contempladas en los contextos escolares.

Estos argumentos me permiten enfatizar en la necesidad de redireccionar los diseños curriculares y los procesos pedagógicos de la educación superior, en tanto que es menester tener presente que, para formar parte de los entornos socioculturales digitales, a la escuela no le basta con cambiar de formato los contenidos: hay que repensar las estructuras y las lógicas, entendiendo que estos nuevos escenarios no solo implican nuevas herramientas, sino que conllevan formas distintas de ser en el mundo que están redimensionando la actuación de los individuos jóvenes en su papel de estudiantes de educación superior, tradicionalmente concebida como pasiva y subsumida a disposiciones institucionales.

El acercamiento realizado es una lectura, de entre muchas posibles, de una realidad profundamente compleja; por ello queda abierta la invitación a ensayar otras preguntas que profundicen sobre las interacciones múltiples que están produciendo formas inéditas de relación social y sus implicaciones en la reconfiguración de las formas de aprender y ser de los jóvenes.

\section{Lista de referencias}

Balaguer, R. (2014). Juventud digital, ¿escucha analógica? Inter Cambios, dilemas $y$ transiciones de la Educación Superior, 2(1), 13-19. Recuperado de: http://intercambios. cse.edu.uy/wp-content/uploads/2014/05/ art1_balaguer.pdf

Balardini, S. (2000). De los jóvenes, la juventud y las políticas de la juventud. Última Década, 13, 11-24. doi:10.4067/S071822362000000200002
Brito, R. (1996). Hacia una Sociología de la Juventud. Algunos elementos para la deconstrucción de un nuevo paradigma de la juventud. Revista de estudios sobre juventud JOVENes, 1(1), 24-33.

Cabero, J., \& Llorente, M. C. (2008). La alfabetización digital de los alumnos. Competencias digitales para el siglo XXI. Revista Portuguesa de Pedagogía, 42(2), 7-28. doi:10.14195/1647-8614_42-2_1

Duarte, K. (2000). ¿Juventud o Juventudes? Acerca de cómo mirar y remirar a las juventudes de nuestro continente. Última Década, 13, 59-77. doi:10.4067/S071822362000000200004

Elizalde, S. (2015). Estudios de la juventud en el cono sur: epistemologías que persisten, desaprendizajes pendientes y compromiso intelectual. Una reflexión en clave de género. Última Década, 42, 129-145. doi:10.4067/S0718-22362015000100007

Erazo, E. (2009). De la construcción histórica de la condición juvenil a su transformación contemporánea. Revista Latinoamericana de Ciencias Sociales, Niñez y Juventud, 7(2), 1303-1329. Recuperado de: http:// revistaumanizales.cinde.org.co/index. php/Revista-Latinoamericana/article/ view/158/63

Feixa, C., Fernández-Planells, A., \& FiguerasMaz, M. (2016). Generación Hashtag. Los movimientos juveniles en la era de la web social. Revista Latinoamericana de Ciencias Sociales, Niñez y Juventud, 14(1), 107-120. doi:10.11600/169271 5x.1416301115

García, N. (2012). Introducción: De la cultura postindustrial a las estrategias de los jóvenes. En N. García-Canclini, F. Cruces, \& M. Urteaga (Comps.) Jóvenes, culturas urbanas y redes digitales (pp. 3-18). Madrid: Fundación Telefónica.

Ibby México. (2015). Primera Encuesta Nacional sobre Consumo de Medios Digitales y Lectura. Recuperado de: http://www.ibbymexico.org.mx/images/ ENCUESTA_DIGITAL_LECTURA.pdf

Inegi. (2017). Encuesta Nacional Sobre Disponibilidad y Uso de Tecnologías de la Información en los Hogares 2016. Instituto 
Nacional de Estadística y Geografía. Recuperado de: www.beta.inegi.org. $\mathrm{mx} / \mathrm{proyectos} /$ enchogares/regulares/ dutih/2016

Kropff, L., \& Stella, V. (2017). Abordajes teóricos sobre las juventudes indígenas en Latinoamérica. Revista LiminaR. Estudios Sociales y Humanísticos, 15(1), 15-28. doi:10.2536/liminar.v15i1.491

Lévy, P. (2004). Inteligencia colectiva: por una antropología del ciberespacio. Washington, D. C.: Organización Panamericana de la Salud.

Morin, E. (2000). El paradigma perdido. Barcelona: Kairós

Ortega, E. (2012). Aprendices, emprendedores y empresarios. En N. García-Canclini, F. Cruces, \& M. Urteaga (Comps.) Jóvenes, culturas urbanas y redes digitales (pp. 111131). Madrid: Fundación Telefónica.

Prensky, M. (2010). Nativos e inmigrantes digitales. Madrid: Cuadernos SEK 2.0.

Santillán, E., \& González, E. (2016). Nociones de Juventud: aportaciones teóricas desde las ciencias sociales. Revista Culturales, 4(1), 113-136. Recuperado de: http://www. scielo.org.mx/pdf/cultural/v4n1/2448539X-cultural-4-01-00113.pdf

Semán, P. (2015). Música, juventud, hegemonía: crítica de una recurrencia. Apuntes de Investigación del Cecyp, 17(5), 119-146. Recuperado de: http://www. apuntescecyp.com.ar/index.php/apuntes/ article/view/536/489

Taguenca, J.A. (2016). Sociología de la juventud. Una revisión. Espacio Abierto, cuaderno venezolano de sociología, 25(3), 183-195. Recuperado de: https://dialnet.unirioja.es/ servlet/articulo? codigo $=5759127$

Ulloa, G. (2016). Tendencias epistémicas sobre la categoría juventud. Una perspectiva foucaultiana. Revista de Ciencias Sociales, 29(38), 103-122. Recuperado de: http://cienciassociales.edu.uy/ departamentodesociologia/wp-content/ uploads/sites/3/2016/07/Articulo-Ulloa. pdf 